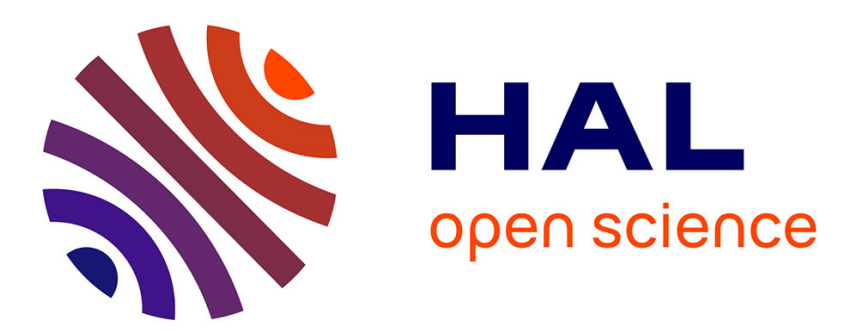

\title{
Effect of Nanoclay Content on Void Morphology in Resin Transfer Molded Composites
}

\author{
Youssef K. Hamidi, Levent Aktas, M. Cengiz Altan
}

\section{To cite this version:}

Youssef K. Hamidi, Levent Aktas, M. Cengiz Altan. Effect of Nanoclay Content on Void Morphology in Resin Transfer Molded Composites. Journal of Thermoplastic Composite Materials, 2008, 21 (2), pp.141-163. 10.1177/0892705707083635 . hal-00570804

\section{HAL Id: hal-00570804 \\ https://hal.science/hal-00570804}

Submitted on 1 Mar 2011

HAL is a multi-disciplinary open access archive for the deposit and dissemination of scientific research documents, whether they are published or not. The documents may come from teaching and research institutions in France or abroad, or from public or private research centers.
L'archive ouverte pluridisciplinaire HAL, est destinée au dépôt et à la diffusion de documents scientifiques de niveau recherche, publiés ou non, émanant des établissements d'enseignement et de recherche français ou étrangers, des laboratoires publics ou privés. 


\title{
Effect of Nanoclay Content on Void Morphology in Resin Transfer Molded Composites
}

\author{
Youssef K. Hamidi, Levent Aktas And M. Cengiz Altan* \\ School of Aerospace and Mechanical Engineering \\ University of Oklahoma, Norman, Oklahoma, 73019
}

\begin{abstract}
Effects of nanoclay content on morphology and spatial distribution of voids in resin transfer molded nanoclay/E-glass/epoxy composite disks are investigated. Closite ${ }^{\circledR} 25 \mathrm{~A}$ nanoclay loads of 2,5 , and $10 \mathrm{wt} \%$ are mixed by sonication with a low-viscosity epoxy resin prior to filling the mold cavity containing $13.6 \%$ E-glass preform by volume. A disk without nanoclay is also molded. Once the molded composites are cured, voids on radial composite samples are evaluated via microscopic image analysis. The addition of nanoclay is found to result in a significant increase in the apparent viscosity of the clay-epoxy mixture, thus increasing the molding pressure. Void occurrence is observed to increase considerably with increasing nanoclay content, from $2.1 \%$ in the composite without nanoclay to 5.1 and $8.3 \%$ in the composites molded with 5 and $10 \mathrm{wt} \%$ nanoclay, respectively. However, the composite with $2 \mathrm{wt} \%$ nanoclay yields the lowest void content of $0.7 \%$. Voids are observed to be, in average, smaller after the addition of nanoclay at all nanoclay concentrations. Presence of nanoclay in the impregnating resin induces at least $60 \%$ reduction in voids located inside fiber tows, which are trapped by the fluid front motion during impregnation. Irregularly shaped voids are also observed to decrease with increasing nanoclay content. A nonuniform void content and morphology is observed radially, which seems to be affected by the flow kinematics as well as possible breakdown and filtration of clay clusters.
\end{abstract}

KEY WORDS: nanocomposites, resin transfer molding, void morphology, nanoclay, void spatial distribution.

\section{INTRODUCTION}

T $\mathrm{N}$ RECENT YEARS, usage of nanoscale fillers in polymers and fiberreinforced composites has attracted considerable interest. Such nanoscale

*Author to whom correspondence should be addressed. E-mail: altan@ou.edu

Journal of Thermoplastic COMPOSITE MATERIAls, Vol. 21-March 2008 
fillers frequently exhibit larger surface area per unit volume and thus enhance the performance of the fabricated composite. One of the most promising of these nanoscale particles is the abundantly available layered silicate, a.k.a. nanoclay. Individual nanoclay particles are silicate platelets that typically range from 1 to $10 \mathrm{~nm}$ in thickness and 1 to $13 \mu \mathrm{m}$ in length [1]. Although nanoclay was first introduced to reinforce thermoplastics such as nylon 6 [2-7], its utilization has been expanded to reinforce thermosetting resins due to their wider industrial usage, higher strength, and lower viscosity [8]. Nanoscale fillers have been also added to fiber-reinforced composites with well-established manufacturing processes in order to improve the mechanical and barrier properties.

Researchers from Toyota [2-7] pioneered the utilization of nanoclay in thermoplastics. They studied effects of adding uniformly dispersed nanoclay into nylon 6 on the mechanical and thermal properties, flame retardancy, as well as water absorption and gas permeability resistance. Usuki et al. reported that the addition of $4 \mathrm{wt} \%$ nanoclay induced a $100 \%$ increase in stiffness and 50\% in strength [5]. A 40\% reduction in maximum water absorption was reported for similar nanocomposites [6]. Kojima et al. [7] also reported an increase in glass transition temperature, $T_{\mathrm{g}}$, of nylon 6 containing $4.7 \mathrm{wt} \%$ nanoclay.

Improved properties are obtained only when nanoclay is intercalated and/ or exfoliated into the polymeric matrix [2-4]. When the clay is well mixed with the polymer matrix, the polymer swells the spacing between platelets and the nanocomposite is called intercalated. When individual clay layers are further dispersed as single platelets into the polymeric matrix, the nanocomposite is called exfoliated. Alexandre and Dubois [9], for instance, showed that mechanical and barrier properties, transparency, and toughness are directly proportional to the degree of exfoliation. Nanoclay dispersion into epoxies also induces significant enhancements in mechanical properties. For example, Advani and Shonaike [10] observed more than 100 and 120\% increase in tensile modulus and strength, respectively after the addition of $5 \mathrm{wt} \%$ nanoclay into an epoxy adhesive. Furthermore, Shah et al. [11] reported a reduction in moisture absorption diffusivity after the introduction of Closite ${ }^{\circledR} 10 \mathrm{~A}$ nanoclay into a molded Derkane epoxy part. A nanoclay load as low as $0.5 \mathrm{wt} \%$ reduced moisture diffusivity by more than $50 \%$, while a $5 \mathrm{wt} \%$ clay load resulted in an $86.4 \%$ reduction in moisture diffusivity. Increases in $T_{\mathrm{g}}$ and tensile modulus with increasing nanoclay contents were also reported [11]. Kinloch and Taylor [12] studied $T_{\mathrm{g}}$ improvements in an epoxy due to the introduction of $10 \mathrm{wt} \%$ of nanoclay. The authors reported a small improvement from 78 to $79^{\circ} \mathrm{C}$ for exfoliated Nanomer ${ }^{\circledR} \mathrm{I} 30 \mathrm{E}$, and a higher $T_{\mathrm{g}}$ of $85^{\circ} \mathrm{C}$ for intercalated Closite ${ }^{\circledR} 25 \mathrm{~A}$. 
Akkapeddi [13], on the other hand, studied both short and continuous glass-fiber-reinforced clay-polyamide 6 nanocomposites manufactured by a melt compounding technique. The author reported improved flexural modulus, strength, and heat distortion temperature under load as well as improved moisture resistance at 2 and $5 \mathrm{wt} \%$ nanoclay contents. Haque et al. [14] reported significant improvements in mechanical and thermal properties of S2-glass/epoxy composites with low nanoclay contents manufactured by vacuum-assisted resin infusion molding (VARIM). The authors observed that dispersing $1 \mathrm{wt} \%$ clay resulted in a $26^{\circ} \mathrm{C}$ increase in $T_{\mathrm{g}}$ as well as 44,24 , and $23 \%$ improvement in interlaminar shear strength, flexural strength, and fracture toughness, respectively. Hussain and Dean [15] utilized the VARIM process to fabricate a series of S2-glass/vinylester nanocomposites containing $0.5,1,2,5$, and $10 \mathrm{wt} \%$ clay. They reported significant improvements in $T_{\mathrm{g}}$, interlaminar shear strength, flexural strength, flexural modulus, and fracture toughness [15]. Becker et al. [16] investigated intercalated clay-epoxy nanocomposites reinforced with $49 \%$ unidirectional carbon fibers. The addition of layered silicate to the prepregs resulted in tougher composites with more than $50 \%$ increase in fracture energy reported for composites containing $2.5,5$, and $7.5 \mathrm{wt} \%$ nanoclay.

Based on the recent results, one can conclude that the addition of nanoclay into a polymeric matrix often yields significant improvements in the mechanical and thermal properties while enhancing moisture resistance. A similar statement can be made for the case of conventional, fiberreinforced composites; however, the extent of improvements still remains uncertain in commercial applications. The effectiveness of using nanoclaypolymer mixtures in current fabrication methods for conventional composites needs to be investigated. For example, the addition of nanoclay increases the bulk viscosity of the polymer, which might require excessive injection pressure for molded composites. For higher nanoclay contents, adequate dispersion and purging of air pockets embedded in clay clusters might not be achieved, even for low viscosity epoxy resins commonly used in liquid composite molding (LCM) processes.

The successful resolution of such fabrication difficulties would facilitate the wider use of nanoclay in both thermosetting and thermoplastic composites. Of particular interest is the resin transfer molding (RTM) process due to the possibility of achieving improved performance at a reduced cost. Resin transfer molding is a well established, versatile process for manufacturing near-net-shape, geometrically complex composite parts. Resin transfer molding typically involves injecting a reacting polymeric resin into a closed mold containing a dry fiber preform. Although large spatial variations in fluid velocity are not observed at the macroscale, local 
microscale velocities can be very different. Wide disparities between local permeabilities and local capillary pressures within the preform often lead to a nonuniform impregnation inside and outside the fiber bundles. This nonuniform velocity field with large spatial variations of velocity gradients leads to the formation of voids in the fabricated composites [17-19]. At higher resin front velocities, resin flow outside fiber tows is much faster than inside, and voids are primarily formed inside the fiber bundles, a.k.a. intra-tow voids. At slower filling rates, on the other hand, capillary flow inside fiber tows leads to impregnation and most of the voids are intertow voids formed outside the fiber bundles. Various researchers reported the existence of an optimum resin velocity at which void formation is minimal and both inter- and intra-tow voids coexist [17-23]. In addition to the described void formation by mechanical entrapment, other void formation mechanisms in RTM composites include initial air bubble content in the resin mixture, volatilization of dissolved gas in the resin during mold filling or curing, and partial evaporation of mold releasing agent into the preform [24]. While mechanical entrapment is inevitable in RTM, the remaining sources of void formation can be eliminated by degassing and proper selection of the resin/preform systems. With the addition of nanoclay, however, initial void content in the resin might be augmented due to the presence of air pockets inside larger clay clusters.

Void presence in composites always yields severe degradation of the mechanical properties [23-26] and resistance to moisture absorption [27,28]. For instance, Ghiorse [25] reported that each 1\% increase in void content induces a $10 \%$ reduction in flexural and interlaminar shear strength, and a $5 \%$ reduction in flexural modulus for carbon/epoxy composites. Goodwin et al. [26] also reported a 7\% reduction in interlaminar shear strength per $1 \%$ increase in voidage up to $10 \%$ for RTM composites containing $57 \%$ 5 -harness satin preform. In addition, even a minor variation in void content is reported to increase the moisture diffusion rate by a factor of 6 [28]. Consequently, void occurrence in RTM composites can be critical in predicting their mechanical performance.

The effect of adding nanoscale fillers on void formation in RTM composites has not yet been studied. In a recent study, Chisholm et al. [29] investigated property enhancement due to the introduction of nanosized $\mathrm{SiC}$ fillers into a carbon/epoxy vacuum assisted resin transfer molded composite. The authors reported qualitatively that nanoparticles tend to reduce void content of the fabricated composites. However, no information on void morphology or spatial void distribution was offered. Understanding void occurrence, morphology, and distribution within the resin transfer, molded nanoclay/E-glass/epoxy composites is believed to be the first step in developing fabrication procedures yielding lower void occurrences 
in such composites. To the best of the authors' knowledge, no such investigation is available in the literature.

In the current study, we investigate the effect of nanoclay on void content, morphology, and spatial void distribution in resin transfer molded, nanoclay/E-glass/epoxy composites. The composite disks containing $13.6 \%$ E-glass preform by volume and 2, 5, and $10 \%$ Closite $^{\circledR} 25 \mathrm{~A}$ nanoclay by weight are fabricated. A composite disk containing only $13.6 \%$ E-glass preform is also molded. In addition to comparing the void contents obtained at different nanoclay loads, more interest is drawn upon morphological features and radial variation of voids to help identify dominant void formation mechanisms.

\section{EXPERIMENTAL}

\section{Materials}

The nanoclay used in this study is Closite ${ }^{\circledR} 25 \mathrm{~A}$ supplied by Southern Clay Products, Inc. Closite ${ }^{\circledR} 25 \mathrm{~A}$ is a natural montmorillonite modified with a quaternary ammonium salt in order to increase the organophilicity of its gallery region, thus improving its dispersion in various types of resins. Typical particle sizes range from 1 to $13 \mu \mathrm{m}$ in length and 1 to $10 \mathrm{~nm}$ in thickness, and its specific gravity is reported as $1.87 \mathrm{~kg} \mathrm{~m}^{-3}$ [1]. The low viscosity epoxy resin EPON $815 \mathrm{C}$ is utilized together with the EPICURE 3282 curing agent commercialized by Shell Chemicals. Preforms used in this study are layers of randomly oriented, chopped-strand, E-glass fibers with a planar density of $0.21 \pm 0.015 \mathrm{~kg} \mathrm{~m}^{-2}$ supplied by Fiberglast (part \#248).

\section{Preparation of the Clay-Epoxy Mixtures}

Prior to the RTM process, the EPON 815C epoxy resin is mixed with the desired amount of Closite ${ }^{\circledR} 25 \mathrm{~A}$ nanoclay. The stoichiometric ratio of 5: 1 of resin to curing agent by weight is considered in order to achieve exact contents of 2,5 , and $10 \mathrm{wt} \%$ of nanoclay in epoxy-curing agent system. Initially, clay-epoxy blends are prepared by sonication. Closite ${ }^{\circledR} 25 \mathrm{~A}$ is first gradually added to the epoxy at room temperature while stirring with a glass rod in a beaker for $5 \mathrm{~min}$. Thereafter, thorough mixing of the blend is performed at $60^{\circ} \mathrm{C}$ in an ultrasonic bath at a frequency of $42 \mathrm{KHz}$. After $60 \mathrm{~min}$, no visual change in the clay-epoxy mixture is observed and the sonication is stopped. The high mixing temperature is selected as higher temperatures normally yield lower viscosities, and thus a better dispersion of the nanoclay. After sonication, the mixture is degassed at room temperature for one additional hour to remove a thin bubble layer formed at top surface. 
Note that before molding of the composite disk without clay, the epoxy resin is subjected to the same sonication process to ensure identical pre-molding conditions for all molded composites. After degassing, the viscosity of each clay-epoxy mixture is measured at $26^{\circ} \mathrm{C}$ using a Brookfield viscometer (Model DV-II+). Note that for clay-epoxy mixtures with 5 and $10 \mathrm{wt} \%$ nanoclay, $1 \mathrm{~h}$ degassing did not eliminate all micro-air bubbles at the top. In order to minimize sedimentation of clay clusters, additional degassing time was not allowed.

\section{Molding Procedure}

Nanocomposite disks used in this study are fabricated by a custom-made experimental molding setup composed of a hydraulic press; two reservoirs for clay-epoxy mixture and curing agent; a static mixer; and a center-gated, disk-shaped mold cavity. Operating the molding press forces the clay-epoxy blend and the curing agent out of the reservoirs into the mold cavity at a constant flow rate. Thorough mixing of these fluids is ensured by a disposable static mixer, yielding a gel time of about $20 \mathrm{~min}$. Six layers of fiber preform are placed in the 3-mm thick mold cavity prior to filling for all disks manufactured in this study. The details of the molding procedure and experimental setup are described in detail elsewhere [21,22]. At the end of mold filling, resin injection is stopped and no further postfill operations are performed in order not to alter void morphology or spatial distribution formed during filling. Molded composite parts are then cured for $48 \mathrm{~h}$ at room temperature before demolding, and sequentially oven-cured for $24 \mathrm{~h}$ at $40^{\circ} \mathrm{C}$. The final molded parts are four composite disks loaded with $0,2,5$, and $10 \mathrm{wt} \%$ Closite $^{\circledR} 25 \mathrm{~A}$ nanoclay, and each containing $13.6 \%$ E-glass fibers by volume. Average thickness and radius of the composite disks are 3.1 and $75.0 \mathrm{~mm}$, respectively.

\section{Microscopic Image Analysis}

The preform planar isotropy and mold axisymmetry simplify the impregnation into a purely radial flow. Consequently, only radial composite samples are examined. A radial specimen is cut from each disk for voidage assessment. Radial variation is assessed by dividing each $75-\mathrm{mm}$ long sample into five 15-mm long regions along the radial direction as shown in Figure 1.

Microscopic image analysis is considered among the most precise methods for measuring void contents [21-25,30,31]. In addition, this technique provides detailed information on other important parameters such as void location, shape, and size that cannot be assessed by other methods. Often, microscopic image analysis is used by averaging randomly selected 


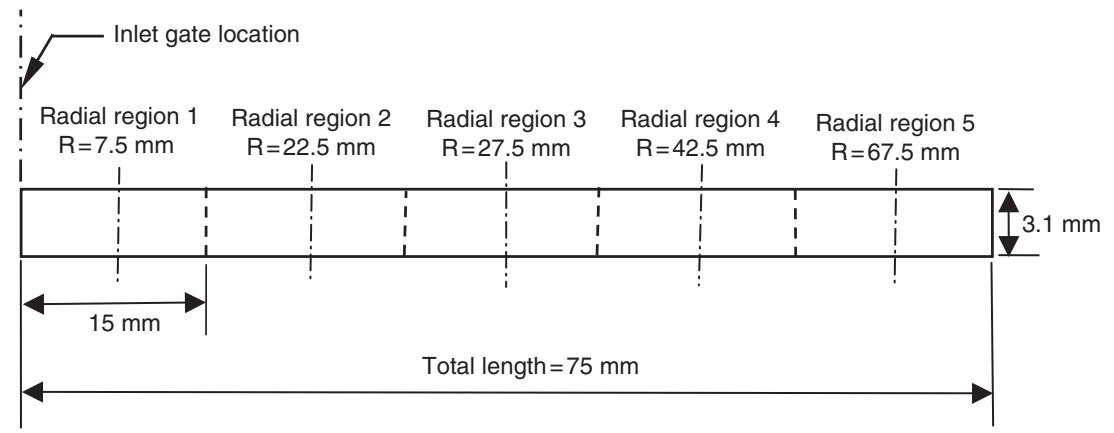

Figure 1. Spatial arrangement of nanocomposite samples into five radial regions for microscopic analysis.

images [30,31]. In the current investigation, however, the studied composite cross-sections are entirely scanned in order to accurately assess void content and morphology. Voidage features are obtained from images acquired at $200 \times$ magnification using a PC-based CCD camera mounted on a MEIJI optical microscope. At this particular magnification, every frame displays approximately $0.71 \mathrm{~mm} \times 0.53 \mathrm{~mm}$. Hence, 720 frames are captured for each composite sample: 6 frames through the thickness direction and 120 along the radial length. The selected magnification of $200 \times$ enables the assessment of voids as small as the radius of a single fiber, i.e. $7 \mu \mathrm{m}$. Consequently, all visually identifiable voids throughout the entire composite samples are included in the analysis of void content and morphology. A total of 15,250 voids are captured manually from the four studied composite samples. Each captured frame is manually processed using the image analysis software Image Tool ${ }^{\circledR}$, which allows the measurement of the area, $A$, and the maximum length, $L_{\max }$ for each void.

\section{RESULTS AND DISCUSSION}

\section{Effect of Nanoclay Content on Mold Filling Parameters}

Figure 2 depicts the effect of nanoclay content on the viscosity of the epoxy. Both nanoclay volume fraction and relative viscosity values are shown with their respective $95 \%$ confidence intervals. The apparent dynamic viscosity increases moderately from $0.65 \mathrm{~Pa} \cdot \mathrm{s}$ for the neat resin to $1.12 \mathrm{~Pa} \cdot \mathrm{s}$ for the $5 \mathrm{wt} \%$ nanoclay suspension. A much steeper increase is observed for concentrated blends. For instance, the viscosity of the mixture reaches $3.69 \mathrm{~Pa} \cdot \mathrm{s}$ at $10 \mathrm{wt} \%$ clay content. For low clay 


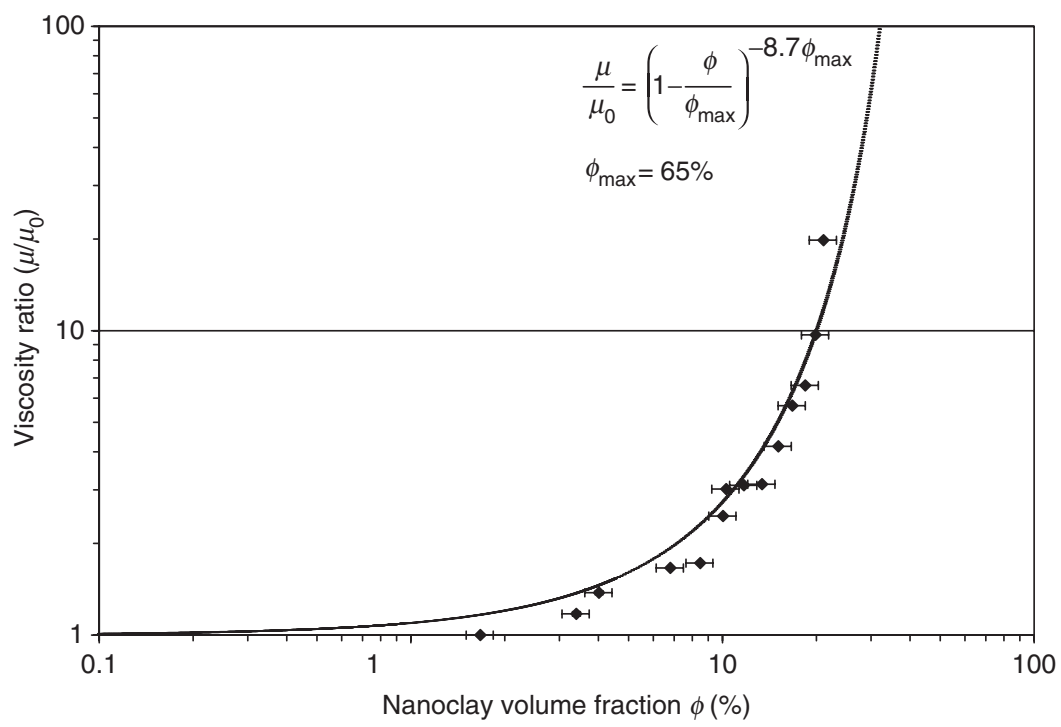

Figure 2. Effect of nanoclay volume fraction, $\phi$, on the viscosity of the epoxy. Epoxy viscosity, $\mu_{0}=0.65$ Pas.

concentrations (i.e., $\phi$ up to $5 \%$ ), the relative viscosity, $\mu / \mu_{0}$, shows linear behavior consistent with the Einstein regime:

$$
\frac{\mu}{\mu_{0}}=1+[\eta] \phi,
$$

where $\mu$ is the suspension apparent viscosity, $\mu_{0}$ the viscosity of the liquid resin, and $\phi$ the filler content. A linear fit to the data yields a value of $[\eta]=8.7$, significantly higher than the value for spheres of 2.5 , which indicates that the nanoclay cluster sizes are quite irregular [33].

As the nanoclay concentration rises, additional dissipative effects are introduced during the flow yielding an increase in the apparent viscosity of the suspension. Suspensions with elevated filler contents are reported in the literature to exhibit non-Newtonian behavior and yield higher viscosities [32-35]. Several methods extending the Einstein description into the nonlinear, concentrated regime can be used to predict the relative viscosity of resin-filler blends. A popular choice is the semi-empirical Krieger and Dougherty model, used recently by different researchers for nanoclay fillers [32-34]:

$$
\frac{\mu}{\mu_{0}}=\left(1-\frac{\phi}{\phi_{\max }}\right)^{-[\eta] \phi_{\max }}
$$


where the relative viscosity, $\mu / \mu_{0}$, diverges asymptotically as the maximum filler content $\phi_{\max }$ is approached. Rather than fitting the data simultaneously with a two parameter nonlinear procedure, the value of $[\eta]$ was taken as that obtained earlier, then a single-parameter nonlinear fit was performed to obtain $\phi_{\max }$. The solid line in Figure 2 represents the best fit to the data, which yields $\phi_{\max }=65 \%$.

The significant increase in apparent bulk viscosity shown in Figure 2 will affect the injection pressure. Knowing that the injection pressure is directly proportional with the apparent viscosity [36], one might expect more than two-fold increase in molding pressure for the resin containing $5 \mathrm{wt} \%$ nanoclay. This increase will be as high as 6 - to 10 -fold if in excess of $10 \mathrm{wt} \%$ clay is added. Such substantial increases in injection pressure may facilitate the formation of smaller voids throughout the composite. However, effective degassing of a highly viscous clay-polymer suspension poses a serious problem. In higher clay loadings, breaking down clay clusters, removing micro-air pockets, and achieving full dispersion might not be possible by mechanical mixing or sonication. Hence, addition of nanoclay above a critical level may adversely affect the final void content in a molded composite.

The apparent viscosity is not the only parameter affected by filler content, the surface tension, $\gamma$, of the clay-epoxy mixture and the contact angle, $\theta$, between fiber and clay-epoxy mixture are affected as well [33-35]. Surface tension and contact angle will change the modified capillary number, $C a^{*}=\mu V / \gamma \cos \theta$, during molding [17-22]. Furthermore, the change in $\mathrm{Ca}^{*}$ will dictate the dominant void morphology. For example, increase in the viscosity will increase $\mathrm{Ca}^{*}$, thus fostering the presence of intra-tow voids inside fiber tows [17-19]. However, increases in surface tension and contact angle can counterbalance these effects and facilitate the formation of larger inter-tow voids.

\section{Effect of Nanoclay Content on Void Occurrence}

Void occurrence of the composites loaded with different nanoclay contents are assessed by microscopic image analysis of through-the-thickness surfaces. Figure 3(a) depicts a microscopic image obtained at $50 \times$ magnification from the composite molded without nanoclay. In order to illustrate differences in nanoclay contents, scanning electron microscope (SEM) images obtained at $50 \times$ magnification from the 2, 5, and 10\%-nanocomposites are shown in Figure 3(b), (c), and (d), respectively. Dispersed nanoclay clusters appear as light grey objects of various sizes in Figure 3(b), (c), and (d).

Resulting void contents and void areal densities of all molded composites are presented in Figure 4. Void occurrence is observed to increase 
(a)

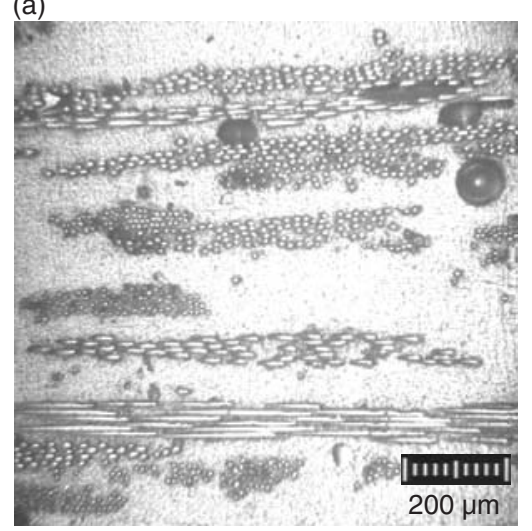

(c)

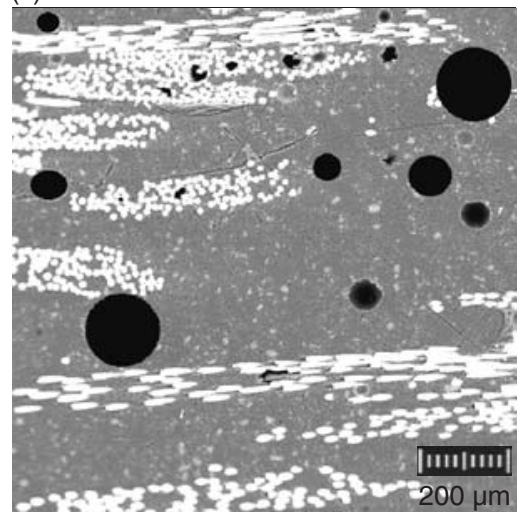

(b)

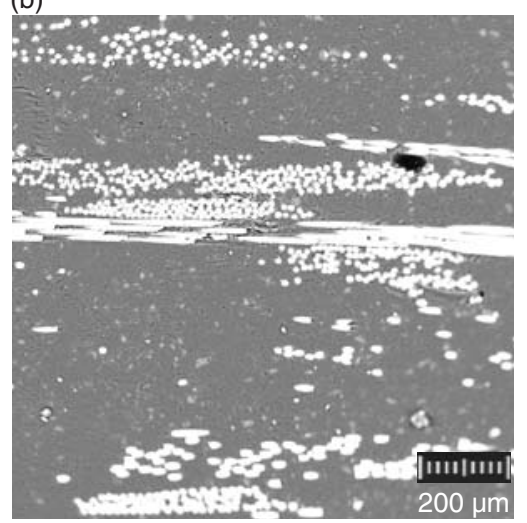

(d)

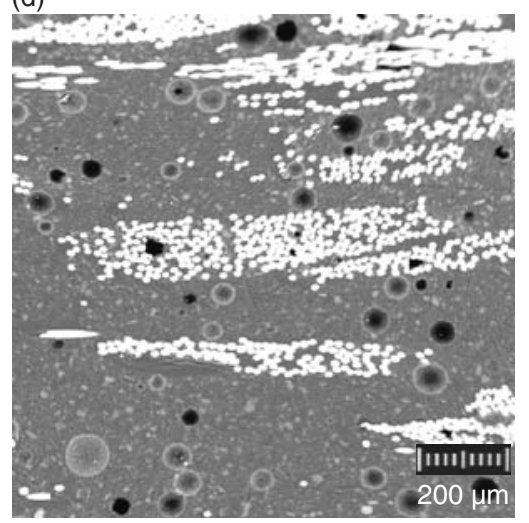

Figure 3. (a) A representative microscopic image obtained at $50 \times$ from the composite molded without nanoclay; and representative SEM images obtained at $50 \times$ from nanocomposites with (b) 2, (c) 5, and (d) $10 \%$ nanoclay content by weight. All images are taken from through-the-thickness surface of the composite samples.

significantly with increasing nanoclay content. In the composite without nanoclay, $2.1 \%$ void content is obtained; whereas with 5 and $10 \mathrm{wt} \%$ nanoclay, void contents are increased to 5.1 and $8.3 \%$, respectively. However, void content is observed to decrease to $0.7 \%$ in the composite with $2 \mathrm{wt} \%$ nanoclay. This initial reduction in void occurrence suggests that the addition of $2 \mathrm{wt} \%$ nanoclay possibly shifts the modified capillary number to a more favorable range, thus helping reduce the void fraction. As discussed in the introduction, impregnation performed at a higher modified capillary number range is known to augment formation of intratow microvoids [17-22]. Reducing void formation in these cases can only be 


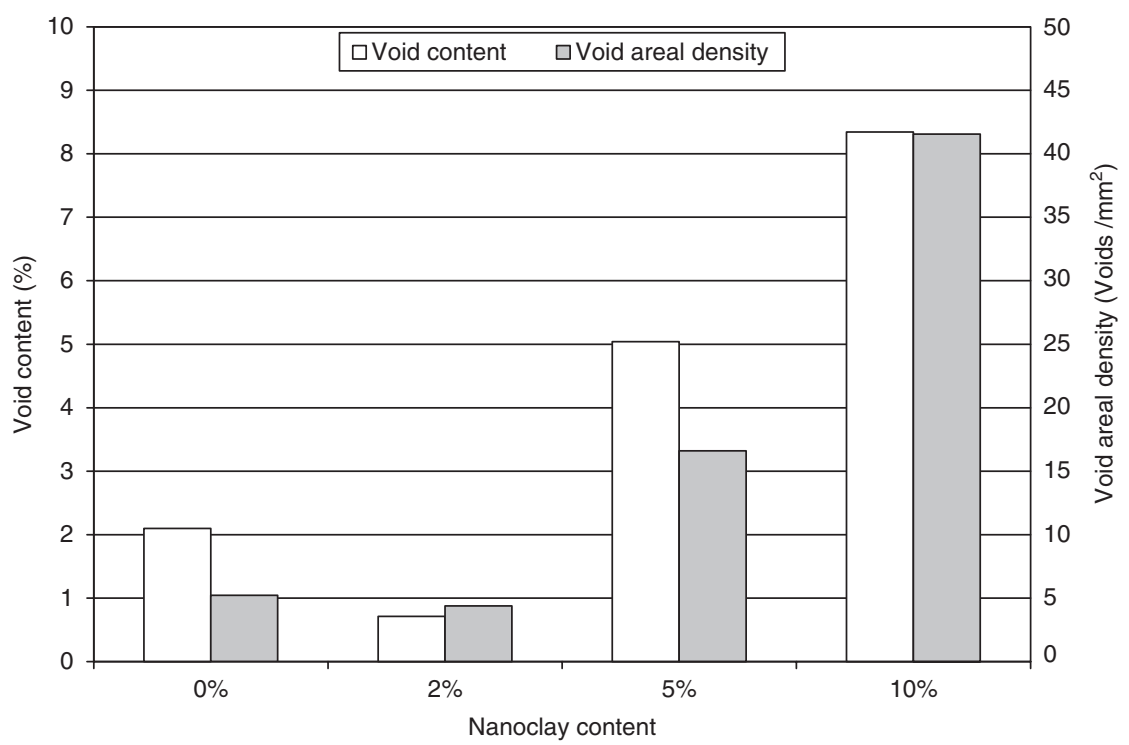

Figure 4. Void contents and void areal densities of composites with different nanoclay contents.

attained by lowering the modified capillary number, which implies a balance between the viscous flows outside fiber tows and the capillary flow inside fiber tows. If such a favorable balance is achieved, then the fluid front inside and between fiber tows progress at the same rate, thus minimizing entrapment of voids by the advancing fluid front. Above $2 \mathrm{wt} \%$ nanoclay, however, void content increases significantly. In addition, void areal densities of 16.6 and 41.6 voids per $\mathrm{mm}^{2}$ attained in the composites containing 5 and $10 \mathrm{wt} \%$ nanoclay, respectively, are sharp increases from the 5.2 voids per $\mathrm{mm}^{2}$ registered in the composite molded without nanoclay. These steep increases in void occurrence might be a result of the initial bubble content or the formation of additional voids via mechanical entrapment. Detailed analysis of void morphology might help understand dominant void formation mechanisms for each nanoclay concentration.

\section{Effect of Nanoclay Content on Void Location}

Proximity of voids to fiber tows can help understand their formation mechanisms as discussed in the introduction. Three different void locations are thus introduced in order to classify observed voids in the molded parts. 
First location is defined as areas primarily composed of reinforcing fibers. Voids in this region are intra-tow voids situated within fiber bundles and are referred to as preform voids. Second location is defined as areas rich in matrix without fibers. Voids encountered in this location are totally surrounded by the clay-epoxy blend and are referred to as matrix voids. The third location is defined as the transitional areas between the two other locations defined here. Voids situated in this location are referred to as transition voids and are always positioned adjacent to, but not within fiber bundles.

Figure 5 depicts contributions from voids encountered at different locations to the total voidage of the composites molded with different clay contents. Matrix voids are negligible in both the 0 and the $2 \%$ nanocomposite as they contribute almost $0.1 \%$ to their respective total void content. However, matrix voids are observed to increase significantly above $2 \mathrm{wt} \%$ clay content reaching 1.59 and $5.81 \%$ for the composites containing 5 and $10 \mathrm{wt} \%$ nanoclay, respectively. Similar trends are observed for void areal densities. This exponential increase in matrix voids occurrence at higher clay concentration can only be explained by elevated initial air bubble levels prior to injection since matrix voids are not likely to form by mechanical entrapment. Apparently, mechanical mixing followed by sonication and degassing were not effective in removing the micro-air pockets within clay clusters when the clay content exceeded $5 \mathrm{wt} \%$. On the other hand, sonication and $60 \mathrm{~min}$ of degassing led to almost void free resins containing 0 and $2 \mathrm{wt} \%$ clay content.

Preform voids, entirely formed by mechanical entrapment, show a different trend. The addition of clay seems to induce a large reduction in void content originating from preform voids. Preform void content is observed to drop from $0.83 \%$ in the composite without clay to $0.20,0.30$, and $0.34 \%$, in the 2,5 , and $10 \%$-nanocomposites, respectively. Simultaneously, preform void areal density slightly increases from 2.49 to $2.61,5.34$, and 5.12 voids per $\mathrm{mm}^{2}$. These large drops (more than $60 \%$ ) in preform void content after the addition of nanoclay to the resin, coupled with slight increases in void areal density indicate that preform voids became significantly smaller at higher clay concentrations. This reduction in the average size of preform voids is likely due to the increased molding pressure experienced during impregnation. Increased pressure would reduce the size of voids at all locations as well as facilitate the break up of larger void formations to smaller sizes. This effect might be one of the reasons of increased void areal density. One can also deduce that adding nanoclay to the resin helps reduce voids formed by mechanical entrapment due to a lower range of modified capillary number as discussed earlier. 

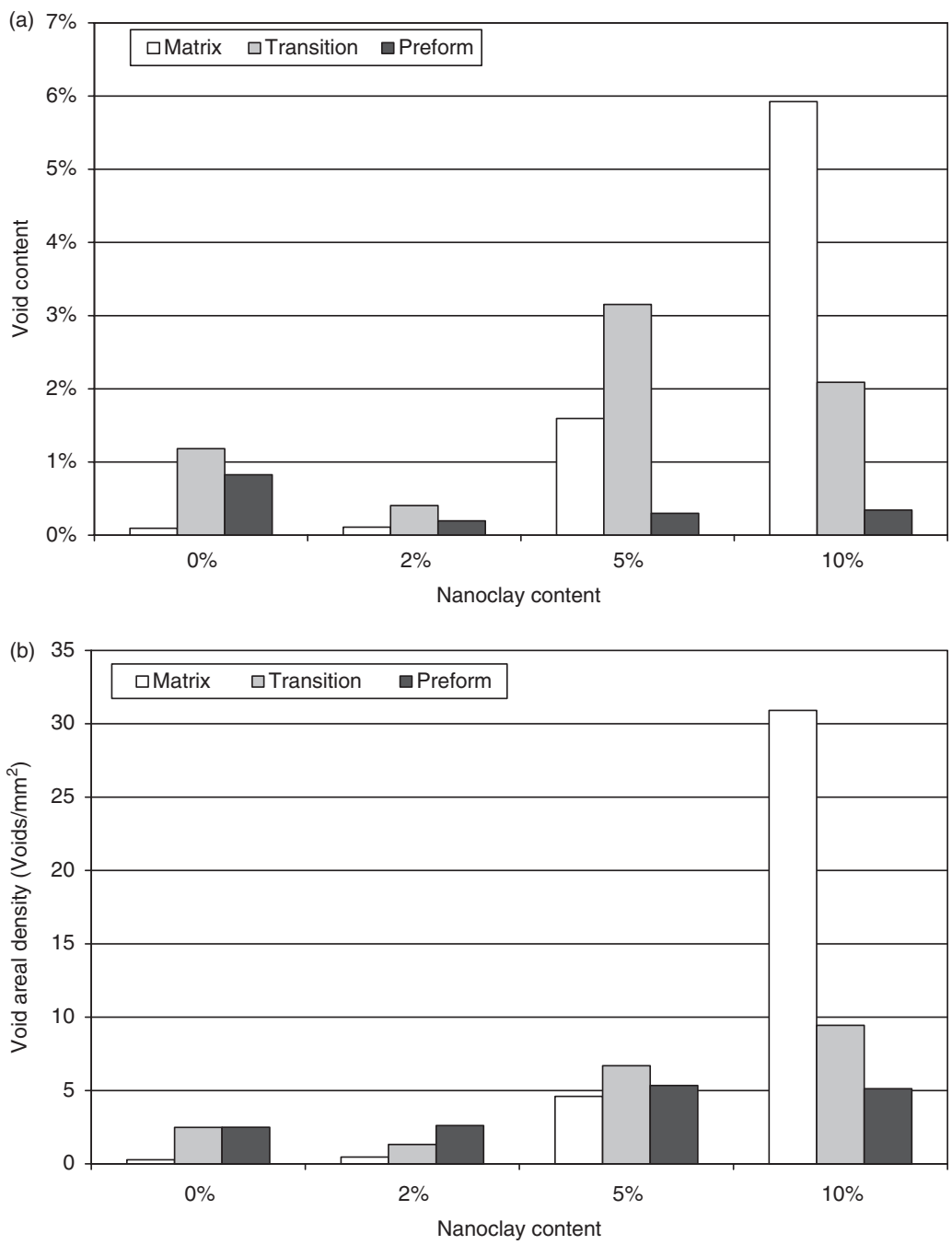

Figure 5. Contributions from voids encountered at different locations to overall voidage in composites with different nanoclay contents: (a) void content, (b) void areal density.

\section{Effect of Nanoclay Content on Void Size}

In order to investigate void size distributions within the molded composites and verify the explanations elaborated above, an equivalent diameter, $D_{\text {eq }}$, is introduced using the measured void area, $A$ :

$$
D_{\text {eq }}=\sqrt{\frac{4 A}{\pi}} \text {. }
$$




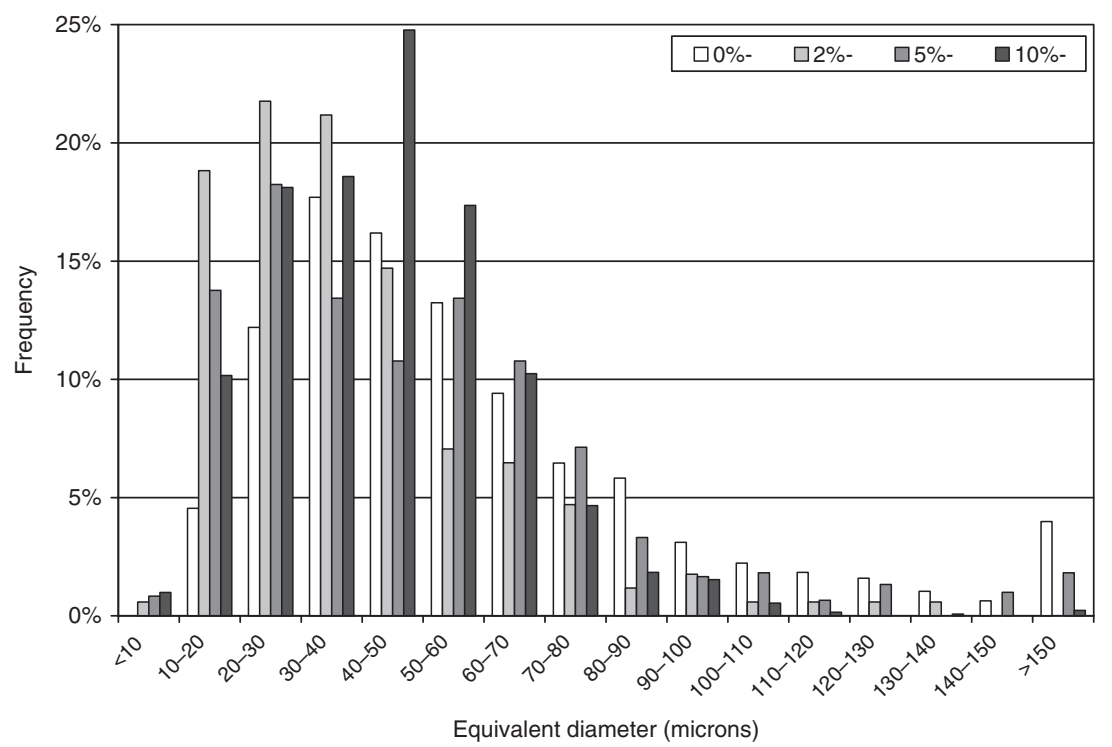

Figure 6. Void size distributions for the composites molded with different nanoclay contents.

The void size distributions for the different composites are presented in Figure 6. The composite molded without nanoclay has an average void size of $59.80 \mu \mathrm{m}$ with a standard deviation of $39.29 \mu \mathrm{m}$; and the highest frequency of $17.70 \%$ is registered for voids with equivalent diameters between 30 and $40 \mu \mathrm{m}$. The composite with $2 \%$ nanoclay has a lower average void size of $39.25 \mu \mathrm{m}$ with a standard deviation of $22.72 \mu \mathrm{m}$, and registered the highest frequency of $21.76 \%$ for voids with equivalent diameters between 20 and $30 \mu \mathrm{m}$. The 5\%-nanocomposite, on the other hand, has an average void size of $50.20 \mu \mathrm{m}$ with a standard deviation of $36.71 \mu \mathrm{m}$. The highest frequency of $18.24 \%$ is registered for voids with equivalent diameters between 20 and $30 \mu \mathrm{m}$. The $10 \%$-nanocomposite has an average void size of $43.98 \mu \mathrm{m}$ with a standard deviation of $20.75 \mu \mathrm{m}$. The highest frequency of $24.77 \%$ is registered for voids with equivalent diameters between 40 and $50 \mu \mathrm{m}$.

Voids are observed to be, in average, smaller after the addition of nanoclay at all concentration levels. This finding is expected since higher clay content would result in higher viscosity and thus a proportionally higher molding pressure. A higher molding pressure is in turn known to shrink formed voids, leading to smaller voids [20-22]. The apparent viscosity of the impregnating resin increased by $17.37,72.37$, and $467.54 \%$ after the addition of 2,5 , and $10 \mathrm{wt} \%$ nanoclay, respectively, which would translate into the same increases in molding pressure. However, average size of voids formed in the $2 \%$-nanocomposite are found to be considerably 


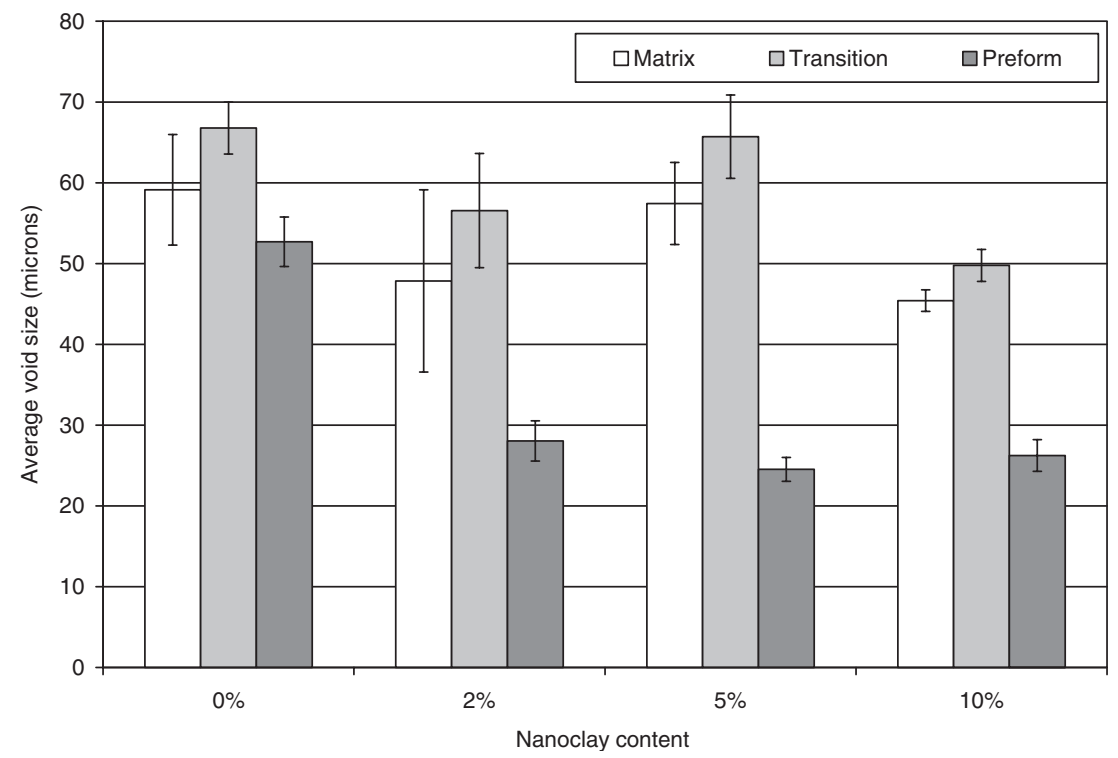

Figure 7. Effect of nanoclay content on average void sizes and on their respective $95 \%$ confidence intervals for voids encountered in different location of each composite.

smaller than those formed in the 5- and 10\%-nanocomposites. To investigate this further, the size distributions of voids encountered at different locations need to be studied. Figure 7 depicts average sizes of voids encountered in different location of each composite, along with their standard deviations. First, note that preform voids are always smaller, in average, than transition and matrix voids. In addition, preform void size is observed to decrease with increasing clay content as described earlier. However, matrix and transition voids do not exhibit a similar steep reduction. For instance, the average void sizes calculated for voids from the matrix and transition locations of the 5\%-nanocomposite are very similar to those calculated for the composite molded without nanoclay. Therefore, higher average void sizes observed in the 5 and $10 \%$-nanocomposites are attributed to much higher occurrences of matrix and transition voids, which are on average much larger than preform voids.

\section{Effect of Nanoclay Content on Void Shape}

Figure 8 shows representative microscopic images of different voids encountered within the molded composites obtained at $200 \times$ magnification. As seen in Figure 8, different void shapes are observed within the studied composites. For example, Figure 8(a), obtained from the composite 
(a)

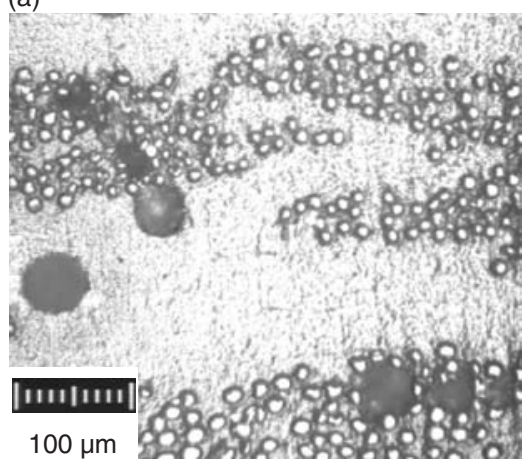

(c)

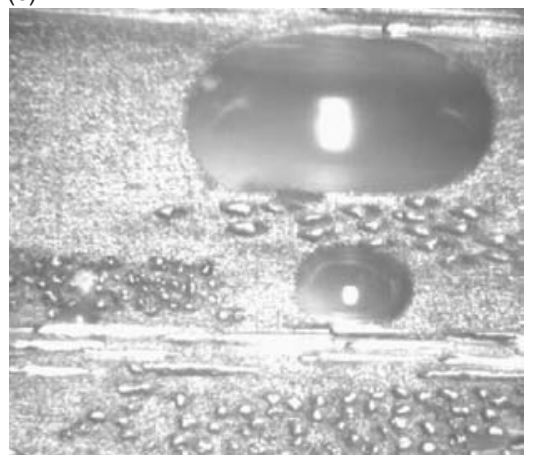

(b)

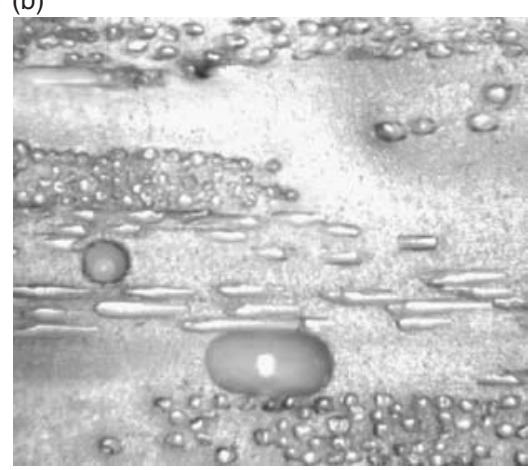

(d)

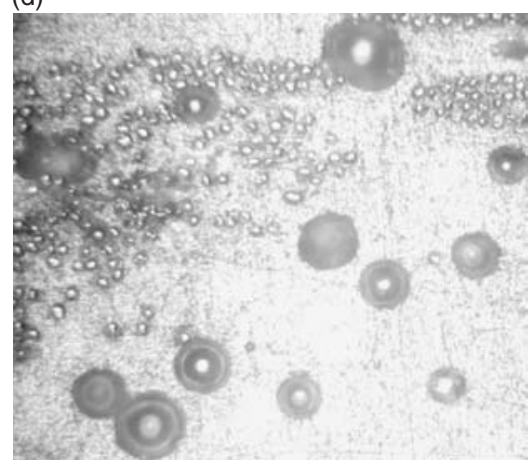

Figure 8. Representative images obtained at $200 \times$ magnification of different voids encountered within the composite containing: (a) 0\%; (b) $2 \%$; (c) $5 \%$, and (d) $10 \%$ nanoclay.

molded without nanoclay, depicts five irregularly shaped voids located within the preform, and two mostly circular voids in the transition and matrix areas. Figure 8(b), obtained from the 2\%-nanocomposite, depicts a circular transition void and a medium elongated transition void. Void shapes are quantitatively analyzed by categorizing them into two groups: irregular and spherical voids. Irregular voids are defined as those within which there exist two different points that can be connected in a straight line that intersects the void boundary. The remaining voids are mostly spherical, although most of them do not present a perfect circular symmetry. To classify this variation in roundness, a shape ratio, $R_{s}$, is introduced for each void as the equivalent diameter obtained from Equation (3) divided by the maximum measured length, $L_{\max }$, within a void:

$$
R_{s}=\frac{D_{\mathrm{eq}}}{L_{\mathrm{max}}}
$$




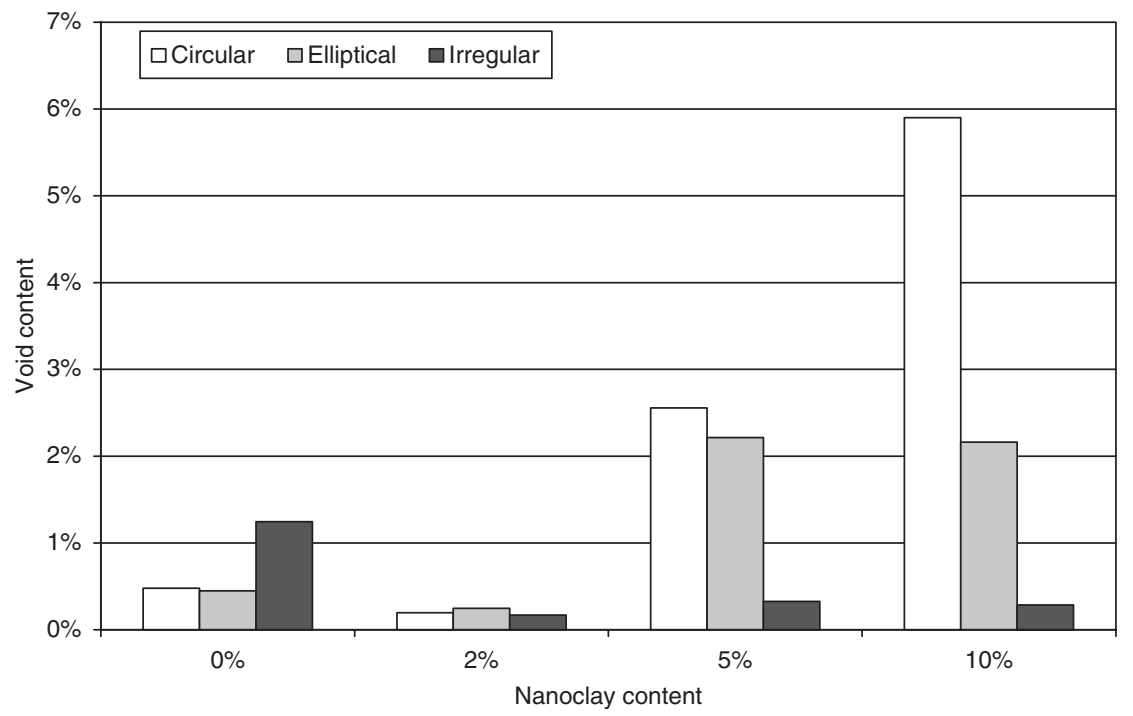

Figure 9. Contributions to void content from voids with different shapes as a function of nanoclay content.

Note that $R_{S}=1$ represents ideal circles, and as the shape ratio decreases, voids become more elongated. Using this shape ratio, spherical voids are further divided into two categories: circular voids with shape ratios above $0.95\left(0.95<R_{s} \leq 1\right)$, and elliptical voids with shape ratios lower than 0.95. For instance, the elongated transition void in Figure 8(b) and the top large elongated transition void in Figure 8(c) both present an $R_{s}=0.76$, while the smaller elongated void shown in Figure 8(c) has an $R_{S}=0.91$.

Using the shape classification defined above, contributions to void content from voids with different shapes are calculated. The resulting shape distributions of voids encountered within the molded composites are presented in Figure 9. Circular and elliptical void content are observed to increase considerably with increasing nanoclay content; conversely, irregular void content is observed to decrease.

For the composite molded without nanoclay, circular and elliptical voids contribute respectively, 0.48 and $0.45 \%$ to the total void content. Circular voids increase dramatically reaching $2.56 \%$ in the $5 \%$-nanocomposite and $5.90 \%$ in the $10 \%$-nanocomposite, while elliptical void content increases only to 2.21 and $2.16 \%$, respectively. Further analysis of void data indicates that in the 5\%-nanocomposite, a vast majority of circular voids are encountered within the matrix or transition locations. Similarly, more than three quarters of elliptical voids in the 5\%-nanocomposite are concentrated in the matrix or transition regions. Even a higher percentage of circular 
and elliptical voids found within the $10 \%$-nanocomposite are categorized as matrix or transition voids. More than $98 \%$ of circular voids and $92 \%$ of elliptical voids are encountered within the matrix or transition locations. Since the vast majority of circular and elliptical voids in both 5 and $10 \%$-nanocomposites are located in matrix or transition regions, one can conclude that the voidage increase experienced by voids with both circular and elliptical voids shown in Figure 9 originate from the micro-air pockets embedded in larger nanoclay clusters, which are transported by the clay-epoxy mixture during impregnation.

On the other hand, irregular voids contribute with $1.24 \%$ to the total void content of the composite molded without nanoclay, i.e. more than half of the total void content. After the addition of 2, 5, and $10 \mathrm{wt} \%$ nanoclay, the contribution of irregular voids to the total void content drops significantly to $0.17,0.33$, and $0.29 \%$, respectively. These observed drops can be attributed to the changes induced in preform voids since most preform voids are confined to the narrow spacing between single fibers and thus present irregular geometries. As observed earlier in Figure 5, preform voids become much smaller after the addition of nanoclay, thus representing a smaller percentage of the total voids. Most likely, the increase in molding pressure at higher clay levels also contributes to the formation of more circular voids as the void deformation induced by flow is counterbalanced by pressure.

\section{Effect of Nanoclay Content on Radial Voidage Variation}

Radial variation of voidage in the molded composites is examined in order to assess the effect of nanoclay content on spatial void arrangements. Each composite sample is divided into five $15-\mathrm{mm}$ long radial regions as shown in Figure 2, and void content in each region is calculated. Figure 10 depicts radial variations of void content in the molded composites. Void contents in the composites containing nanoclay do not seem to show clear radial trends. However, radial void contents of the composite molded without nanoclay appear to follow predictions of the capillary analysis [17-22,37,38]. Because the mold filling is performed at a constant injection rate, the fluid front velocity decreases with increasing distance from injection gate. For the range of modified capillary number, $\mathrm{Ca}^{*}$, of the composite molded without nanoclay, the viscous flow leads to the capillary flow $[21,22]$. Thus, slower fluid front velocity is expected to trap fewer and smaller voids inside fiber bundles towards the outer edges of the disk $[37,38]$. This latter fact might explain the sharp decrease of void content from 3.96 to $1.26 \%$ between the first and third radial regions of the composite molded without nanoclay. Matrix and transition voids formed 


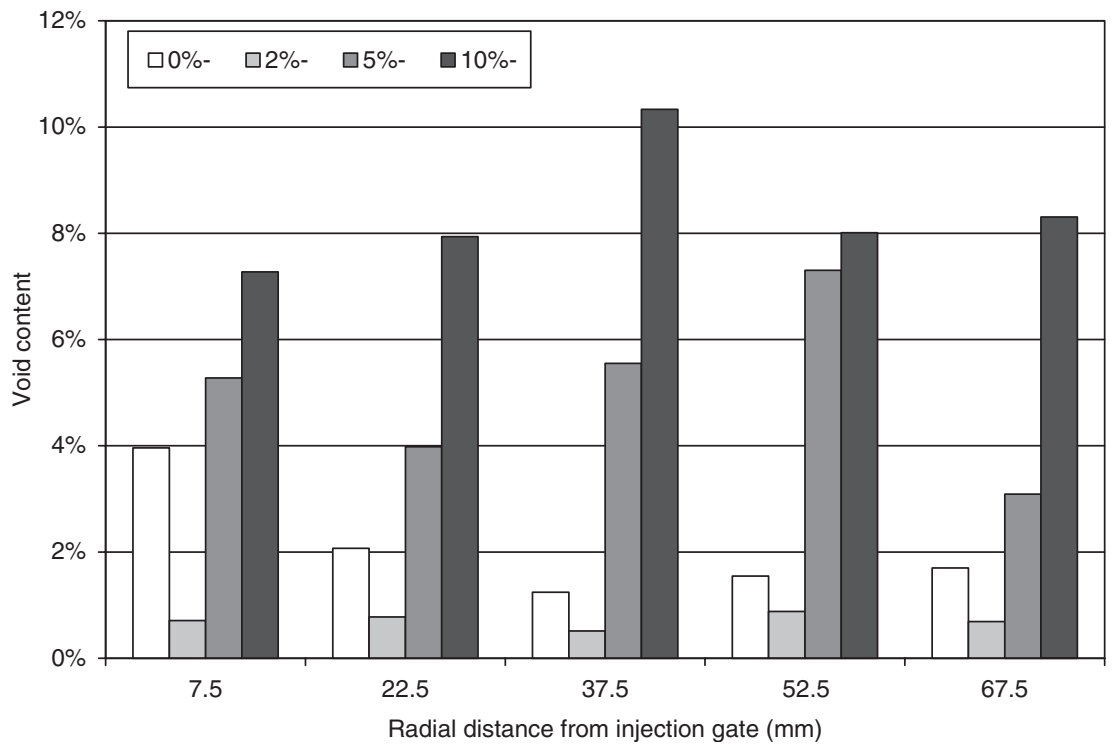

Figure 10. Radial variation of void content in the composites containing $0,2,5$, and $10 \%$ nanoclay.

during mold filling are relatively free to move and might be transported to the last two radial regions by the flow yielding slightly higher void contents of 1.55 and $1.70 \%$ in the fourth and fifth regions, respectively. The 2\%-nanocomposite, on the other hand, exhibits lower void contents limited between a minimum of $0.51 \%$ at the third radial region and a maximum of $0.88 \%$ in the fourth. These comparable low void occurrences are consistent with an equilibrium between the viscous and capillary flows during mold filling as suggested earlier. Finally, no clear radial trend in void content could be detected for the 5- and 10\%-nanocomposites since the air bubbles embedded in clay clusters dominate the void morphology, as well as size and location distributions.

In order to investigate the radial variation of voids formed during the impregnation process, only those voids formed by mechanical entrapment by the fluid front are utilized. Hence, the effect of pre-existing voids embedded in or trapped by the larger clay clusters is eliminated. This is achieved by considering the radial variation of only preform voids as presented in Figure 11. Preform void content for the composite molded without nanoclay is observed to decrease gradually from $2.09 \%$ in the first region to $0.35 \%$ in the fifth as predicted by the capillary number analysis. For the 2\%-nanocomposite, preform void content is also observed to 


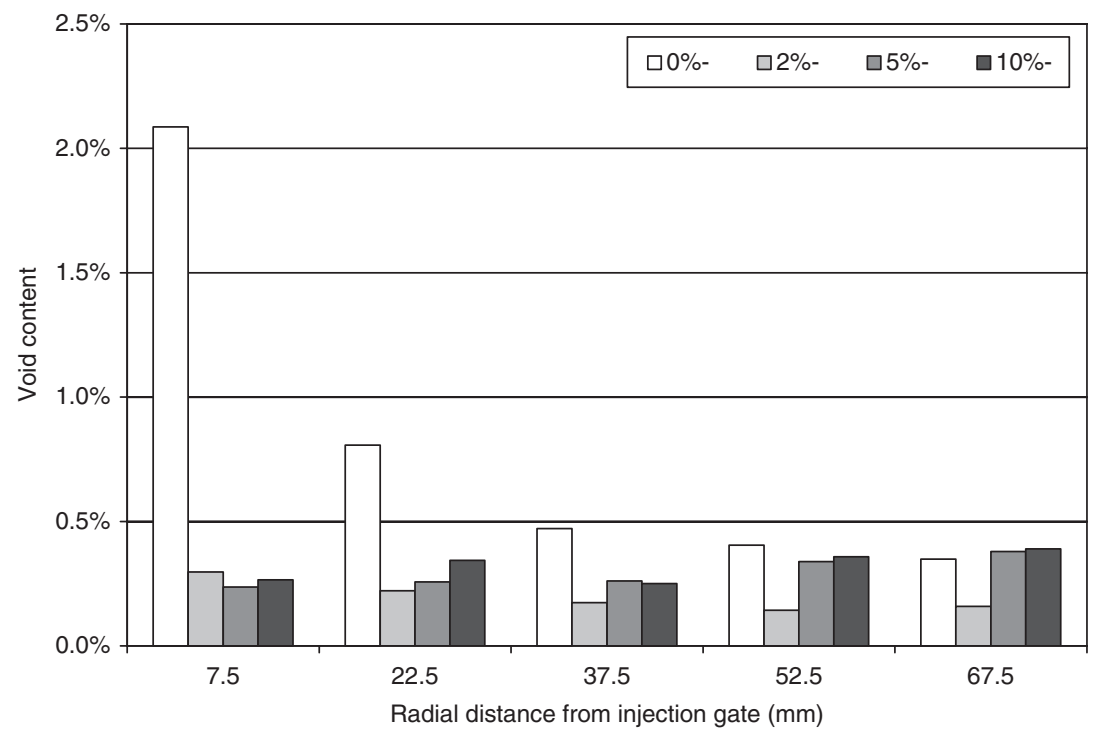

Figure 11. Radial variation of preform void content in the composites containing $0,2,5$, and $10 \%$ nanoclay.

decrease from 0.30 to $0.16 \%$ between the first and fifth regions. The much lower void occurrences corroborate that a certain equilibrium is reached between viscous and capillary forces as suggested earlier.

According to the capillary number analysis, void content of voids formed by mechanical entrapment (i.e., preform voids) is expected to decrease with decreasing fluid front velocity, i.e. away from the inlet $[21,22,37,38]$. Yet, radial variations of the preform void content obtained from both 5- and $10 \%$-nanocomposites show a slight increase with increasing radial distance. Preform voids gradually increase from 0.24 to $0.38 \%$ along the five radial regions of the 5\%-nanocomposite, while a similar $45 \%$ increase from 0.27 to $0.39 \%$ is observed for the $10 \%$-nanocomposite. Again, the low occurrence of preform voids implies the existence of an equilibrium between viscous and capillary flows. However, the radial increases can be a result of changes in the bulk properties of the impregnating fluid such as the apparent viscosity, contact angle, and surface tension yielding higher voids entrapment inside the preform. Breakdown of nanoclay clusters in the radial direction has been reported for similar composite disks [39], which would contribute to the variation of bulk fluid properties during mold filling. Clay filtration is also probable, especially for 5 and $10 \mathrm{wt} \%$ nanoclay content, yielding lower concentrations of clay in the impregnating fluid towards the outer edge of the molded disks. Thus, nonuniform 
values of apparent viscosity, surface tension, and contact angle are expected at the fluid front during mold filling. These changes in bulk fluid properties and the radially decreasing fluid front velocity slightly augment mechanical entrapment of voids at higher clay concentrations as shown in Figure 11.

\section{CONCLUSIONS}

Effect of adding nanoclay on the formation, morphology, and spatial distribution of voids in resin transfer molded nanoclay/E-glass/epoxy composite disks are presented. Mixing of Closite ${ }^{\circledR} 25 \mathrm{~A}$ nanoclay with the low viscosity EPON $815 \mathrm{C}$ resin leads to a significant increase in the resin viscosity, and thus in the injection pressure. Almost 6-fold increase in the injection pressure is estimated for the resin containing $10 \mathrm{wt} \%$ nanoclay. Overall void content is observed to increase from $2.1 \%$ in the composite disk molded without nanoclay to 5.1 and $8.3 \%$ in the composites containing 5 and $10 \mathrm{wt} \%$ nanoclay, respectively. The addition of $2 \mathrm{wt} \%$ nanoclay yields the lowest void content at $0.7 \%$. The increased void content in composites molded with 5 and $10 \mathrm{wt} \%$ clay is due to the pre-existence of air pockets embedded in clay clusters, which could not be removed by mechanical mixing, sonication, or degassing. These air pockets usually appear as 40 - to $60-\mu \mathrm{m}$ circular voids surrounded by the epoxy resin, thus forming bulk of so-called matrix voids. Voids are observed to be smaller on average after the addition of nanoclay at all concentrations. Presence of nanoclay in the resin induced at least $60 \%$ reduction in voids located within the fiber preform. Irregularly shaped voids are also observed to decrease with increasing nanoclay content. Along the radial direction of the molded disks, an increase in preform voids, which are formed by mechanical entrapment, is observed at higher nanoclay levels.

\section{REFERENCES}

1. Typical Physical Properties Bulletin, Southern Clay Products, Inc. 2004.

2. Usuki, A., Kawasumi, M., Kojima, Y., Okada, A., Kurauchi, T. and Kamigaito, O. (1993). Swelling Behavior of Montmorillonite Cation Exchanged for $\omega$-Amino Acids by $\varepsilon$-Caprolactam, Journal of Materials Research, 8: 1174-1178.

3. Usuki, A., Kojima, Y., Kawasumi M, Okada, A., Fukushima, Y., Kurauchi, T. and Kamigaito, O. (1993). Synthesis of Nylon 6-Clay Hybrid, Journal of Materials Research, 8: 1179-1184.

4. Kojima, Y., Usuki, A., Kawasumi, M, Okada, A., Kurauchi, T. and Kamigaito, O. (1993). Synthesis and Properties of Polyimide-Clay Hybrid, Journal of Polymer Science, Part A: Polymer Chemistry, 31: 2493-2498.

5. Kojima, Y., Usuki, A., Kawasumi, M., Okada, A., Kurauchi, T. and Kamigaito, O. (1993). One-Pot Synthesis of Nylon 6-Clay Hybrid, Journal of Polymer Science, Part A: Polymer Chemistry, 31: 1755-1758. 
6. Kojima, Y., Fukumori, K., Usuki, A., Okada, A. and Kurauchi, T. (1993). Gas Permeabilities in Rubber-Clay Hybrid, Journal of Materials Science Letters, 12: 889-890.

7. Kojima, Y., Usuki, A., Kawasumi, M, Okada, A., Fukushima, Y., Kurauchi, T. and Kamigaito, O. (1993). Mechanical Properties of Nylon 6-Clay Hybrid, Journal of Materials Research, 8: 1185-1189.

8. Isik, I., Yilmazer, U. and Bayram, G. (2003). Impact Modified Epoxy/Montmorillonite Nanocomposites: Synthesis and Characterization, Polymer, 44: 6371-6377.

9. Alexandre, M. and Dubois, P. (2000). Polymer-Layered Silicate Nanocomposites: Preparation, Properties and Uses of a New Class of Materials, Materials Science and Engineering, 28: 1-63.

10. Advani, S.G. and Shonaike, G.O. (2003). Advanced Polymeric Materials: Structure Property Relationships, CRC Press, 349-396.

11. Shah, A.P., Gupta, R.K., Gangarao, H.V.S. and Powell, C.E. (2002). Moisture Diffusion Through Vinyl Ester Nanocomposites Made with Montmorillonite Clay, Polymer Engineering and Science, 42: 1852-1863.

12. Kinloch, A.J. and Taylor, A.C. (2003). Mechanical and Fracture Properties of Epoxy/ Inorganic Micro- and Nano-Composites, Journal of Materials Science Letters, 22: 1439-1441.

13. Akkapeddi, M.K. (2000). Glass Fiber Reinforced Polyamide-6 Nanocomposites, Polymer Composites, 21: 576-585.

14. Haque, A., Shamsuzzoha, M., Hussain, F. and Dean, D. (2003). S2-Glass/Epoxy Polymer Nanocomposites: Manufacturing, Structures, Thermal and Mechanical Properties, Journal of Composite Materials, 37: 1821-1837.

15. Hussain, F. and Dean, D. (2002). Thermal and Mechanical Properties of Vinylester Based Layered Silicate Nanocomposites, International SAMPE Technical Conference (M\&P-Ideas to Reality), 34: 692-704.

16. Becker, O., Vareley, R.J. and Simon, G.P. (2003). Use of Layered Silicates to Supplementarily Toughen High Performance Epoxy-Carbon Fiber Composites, Journal of Materials Science Letters, 22: 1411-1414.

17. Patel, N. and Lee, L.J. (1995). Effects of Fiber Mat Architecture on Void Formation and Removal in Liquid Composite Molding, Polymer Composites, 16: 386-399.

18. Mahale, A.D., Prud'Homme, R.K. and Rebenfeld, L. (1992). Quantitative Measurement of Voids Formed During Liquid Impregnation of Nonwoven Multifilament Glass networks Using an Optical Visualization Technique, Polymer Engineering and Science, 32: 319-326.

19. Patel, N., Rohatgi, V. and Lee, J.L. (1995). Micro Scale Flow Behavior and Void Formation Mechanism During Impregnation Through a Unidirectional Stitched Fiberglass Mat, Polymer Engineering and Science, 35: 837-851.

20. Rohatgi, V., Patel, N. and Lee, J.L. (1996). Experimental Investigation of Flow Induced Microvoids During Impregnation of Unidirectional Stitched Fiberglass Mat, Polymer Composites, 17: 161-170.

21. Barraza, H.J., Hamidi, Y.K., Aktas, L., O'Rear, E.A. and Altan, M.C. (2003). Porosity Reduction in the High-Speed Processing of Glass Fiber Composites by Resin Transfer Molding (RTM), Journal of Composite Materials, 38: 195-226.

22. Hamidi, Y.K., Aktas, L. and Altan, M.C. (2004). Formation of Microscopic Voids in Resin Transfer Molded Composites, Journal of Engineering Materials and Technology, 126: $420-426$.

23. Olivero, K.A., Barraza, H.J., O'Rear, E.A. and Altan, M.C. (2002). Effect of Injection Rate and Post-Fill Cure Pressure on Resin Transfer Molded Disks, Journal of Composite Materials, 36: 2011-2028.

24. Stabler, W.R., Tatterson, G.B., Sadler, R.L. and El-Shiekh, A.H.M. (1992). Void Minimization in the Manufacture of Carbon Fiber Composites by Resin Transfer Molding, SAMPE Quarterly, 23: 38-42. 
25. Ghiorse, S.R. (1993). Effect of Void Content on the Mechanical Properties of Carbon/ Epoxy Laminates, SAMPE Quarterly, 23: 54-59.

26. Goodwin, A.A., Howe, C.A. and Paton, R.J. (1997). The Role of Voids in Reducing the Interlaminar Shear Strength in RTM Laminates, Proc. ICCM-11, Australian Composite Structures Society, IV: 11-19.

27. Harper, B.D., Staab, G.H. and Chen, R.S. (1987). A Note on the Effect of Voids upon the Hygral and Mechanical Properties of AS4/3502 Graphite/Epoxy, Journal of Composite Materials, 21: 280-289.

28. Hoppel, C., Bogetti, T. and Newill, J.F. (2000). Effects of Voids on Moisture Diffusion in Composite Materials, Proc. the American Society for Composites 15th Technical Conference, pp. 1094-1102.

29. Chisholm, N., Mahfuz, H., Rangari, V. K., Ashfaq, A. and Jeelani, S. (2005). Fabrication and Mechanical Characterization of Carbon/SiC-Epoxy Nanocomposites, Composite Structures, 67: 115-124.

30. Ghiorse, S.R. (1991). A Comparison of Void Measurement Methods for Carbon/Epoxy Composites, US Army Materials Technology Laboratory. Report MTL-TR 91-13.

31. Santulli, C., Garcia Gil, R., Long, A.C. and Clifford, M.J. (2002). Void Content Measurement in Commingled E-Glass/Polypropylene Composites using Image Analysis from Optical Micrographs, Science and Engineering of Composite Materials, 10: 77-90.

32. Wang, H., Elkovitch, M., Lee, L.J. and Koelling, K.W. (2000). Processing and Properties of Polymer Nano-Composites, Proc. 58th Annual Technical Conference-Society of Plastics Engineers, 2: 2402-2406.

33. Kugge, C. and Daicic, J. (2004). Shear Response of Concentrated Calcium Carbonate Suspensions, Journal of Colloid and Interface Science, 271: 241-248.

34. Kislenko, V.N and Verlinskaya, R.M. (2001). Rheological Behavior of Kaolin and Montmorillonite Suspensions at Low Concentrations, Journal of Colloid and Interface Science, 244: 405-409.

35. Khil, M.S., Kim, H.Y., Kim, M.S., Park, S.Y. and Lee, D.-R. (2004). Nanofibrous Mats of Poly(Trimethylene Terephthalate) via Electrospinning, Polymer, 45: 295-301.

36. Olivero, K.A., Hamidi, Y.K., Aktas, L. and Altan, M.C. (2004). Effect of Preform Thickness and Volume Fraction on Injection Pressure and Mechanical Properties of Resin Transfer Molded Composites, Journal of Composite Materials, 38: 937-958.

37. Hamidi, Y.K. and Altan, M.C., (2003). Spatial Variation of Void Morphology in Resin Transfer Molded E-Glass/Epoxy Composites, Journal of Materials Science Letters, 22: 1813-1816.

38. Hamidi, Y.K., Aktas, L. and Altan, M.C. (2005). Three-Dimensional Features of Void Morphology in Resin Transfer Molded Composites, Composites Science and Technology, 65: $1306-1320$.

39. Aktas, L., Dharmavaram, S., Hamidi, Y.K. and Altan, M.C. (2005). Quantitative Analyses of Nanoclay Dispersion in Molded Epoxy Disks: Effects of Mixing Temperature, Nanomaterials: New Research, pp. 197-218, Nova Science Publishers, New York. 